\title{
CIDADE NOVA OU CIDADE DAS LÁGRIMAS?: A CONSTRUÇ̃̃O DO TERCEIRO BAIRRO OFICIAL DE NATAL NO INÍCIO DO SÉCULO XX
}

\author{
CIDADE NOVA OR TOWN OF TEARS?: THE BUILDING OF THE \\ THIRD OFFICIAL DISTRICT IN NATAL AT THE BEGINNING OF \\ THE XXth CENTURY
}

\begin{abstract}
RESUMO: Esse artigo objetiva compreender o processo de construção de Cidade Nova no início do século XX, terceiro bairro oficial de Natal (Rio Grande do Norte), em meio a uma nova realidade que surgiu no estado com a construção do regime republicano. Observa-se em Cidade Nova a construção de um novo território material e simbólico: a área que outrora era ocupada por casebres construídos pelos retirantes da seca, foi, a partir do início do século XX, desocupada e transformada, esquadrinhada por meio de plano urbanístico. O discurso oficial propagava os anseios dos grupos dirigentes em construir em Cidade Nova um bairro aprazível, modernizado em suas estruturas, que refletisse o novo momento pelo qual a cidade passava. Contudo, é possível constatar que o processo de construção de Cidade Nova não representou apenas mudanças, não foi característico somente de um processo de modernização. Esse processo foi marcado por continuidades e ambivalências, por derrubadas de casebres, desapropriações e violência, demonstrando como a modernização da capital norte-rio-grandense foi limitada e guiada por um grupo específico. Para demonstrar as limitações desse processo comparou-se o discurso oposicionista sobre o processo de desapropriações existente em Cidade Nova, divulgado no jornal Diário do Natal, com o discurso oficial veiculado no jornal A Republica. O cruzamento dessas versões é o que dá subsídios para constatar se a construção de Cidade Nova como discurso de bairro modernizado, novo, progressista, teria mesmo concretizado-se.
\end{abstract}

PALAVRAS-CHAVE: Natal. Cidade Nova. Desapropriações.

ABSTRACT: This article aimed to understand the process of constructing the neighborhood Cidade Nova in the early twentieth century, third district oficial in Natal (Rio Grande do Norte), in the midst of a new reality that emerged in the state with the construction of the republican regime. It is observed in Cidade Nova building a new spatiality material and symbolic: the area that was once occupied by huts built by migrants from drought, was, from the beginning of the twentieth century, unoccupied and transformed scanned through urban plan. The official discourse propagated the desires of ruling groups to build a delightful neighborhood in Cidade Nova, modernized its structures to reflect the new time by which the city passed. However, it was established that the process of construction of the Cidade Nova is not only represented changes, was not only characteristic of a process of modernization. This process was marked by continuities and ambivalences, by clearing of hovels, expropriations and violence, demonstrating how the modernization of the capital of Rio Grande do Norte was limited and guided by a specific group. To demonstrate the limitations of this process compared the oppositionist discourse on the process of expropriation exists in Cidade Nova, published in newspaper Diário do Natal with the official speech propagated in the newspaper A Republica. The intersection of these versions is what gives grants to demonstrate the construction of Cidade Nova neighborhood as discourse modernized, new, progressive, would have even brought up.

KEYWORDS: Natal. Cidade Nova. Expropriations. 


\section{Considerações iniciais}

O bairro Cidade Nova foi resultado de um plano de expansão elaborado para Natal no início do século XX, em um contexto de transição do período imperial para o republicano. ${ }^{1} \mathrm{~A}$ transição do século XIX para o XX foi marcada por mudanças. A instituição República proporcionou novos mecanismos e novas relações nos estados brasileiros, que ganharam maior autonomia e puderam modificar suas relações de dominação e identidade.

Com a República, tem-se a Constituição de 1891, que concedeu maior liberdade aos estados, a receita de exportação pôde ser revertida para as próprias unidades federativas e as representações políticas estaduais passaram a ser mais autônomas (CARONE, 1983). Nesse período, tem-se a elaboração de constituintes estaduais que também concederam aos municípios maior liberdade administrativa e financeira, autonomia que favoreceu o uso pessoal do dinheiro público em obras particulares. Manteve-se um liberalismo de representação limitada e restritiva, em que o jogo do poder local e estadual era restrito aos membros mais abastados e influentes (RESENDE, 2010, p.98).

A identidade e a espacialidade norte-rio-grandense foram gestadas nesse período de transição e ascensão do regime republicano. Para Peixoto, durante o Império, em que a preocupação era com a identidade e espacialidade nacional, as tensões locais existentes por disputas de grupos familiares nas províncias eram deslocadas espacialmente. Os membros desses grupos não ocupavam cargos apenas no interior dos limites de suas províncias. Ao contrário, esses membros eram designados para ocupar cargos em diversas espacialidades, a serviço do Estado, desconstruindo um dos sentidos de atuação dessas organizações e permitindo "a incorporação destas organizações familiares ao projeto de Nação e deslocando as tensões para outro nível de discussão, no sentido da permanência da centralidade do Estado", representado pelo Imperador e pelo Parlamento sediado no Rio de Janeiro" (AMADO, 2012, p.19).

Ainda segundo Peixoto, foi nesse período que uma nova organização familiar assumiu o poder no estado, e seus interesses deixaram de ser conquistados por meio de uma ordem baseada na fluidez do espaço, que diluía as tensões. Nessa nova realidade, as ambições dos grupos familiares só seriam atendidas por meio do controle do aparelho local e, sobretudo, do estadual. Controlando o governo estadual, as organizações familiares poderiam dispor dos

\footnotetext{
${ }^{1} \mathrm{O}$ bairro Cidade Nova foi dividido oficialmente em dois bairros, Petrópolis e Tirol, em 1947, ver: NATAL. Câmara Municipal. Projeto de Lei 251, de 20 de julho de 1947. Natal: 1947.
}

Oficina do Historiador, Porto Alegre, EDIPUCRS, v. 7, n. 1, jan./jun. 2014, p. 63-84. 64 
recursos de uma unidade estadual e conseguir mais benefícios por meio de seus representantes junto ao governo central. Dessa maneira, para justificar e legitimar essa organização familiar que assumiu o poder no Rio Grande do Norte no cenário republicano, fazia-se necessário construir um discurso, uma narrativa que remetesse esse poder a um passado sagrado, um discurso articulado a um passado que ele mesmo construía (PEIXOTO, 2012, p.23).

Assim, o grupo familiar Albuquerque Maranhão, que assumiu o poder no estado com a República, esforçou-se em construir uma espacialidade e identidade norte-rio-grandense, representando esse período como promissor, como diferente do anterior, do imperial, em que a cidade era permeada de características provincianas e atrasadas. Tratava-se de um momento em que esses grupos dirigentes queriam afirmar-se na cidade, e, para tanto, inscreviam-se nas toponímias da urbe, nos novos espaços criados, como o bairro Cidade Nova, e, especialmente, na historiografia estadual e local, que começou a ser escrita e disseminada nesse período. ${ }^{2}$ Nesse discurso, Cidade Nova era representada enquanto símbolo do progresso, como exemplo máximo da modernização da capital norte-rio-grandense. ${ }^{3}$

Entretanto, a análise das fontes demonstrou que não se tratou apenas de um discurso. Ocorreram reformas na capital norte-rio-grandense, como a abertura de ruas, o planejamento e execução de planos urbanísticos, a introdução de bondes e outros equipamentos técnicos. Reformas que também provocaram transformações sociais, que mudaram a forma dos indivíduos relacionarem-se com os espaços da cidade. As leis e decretos estaduais, bem como as resoluções municipais publicadas nesse período demonstram essa tentativa de modificar os espaços da cidade, mudar os costumes, os hábitos da população. Todavia, as análises das fontes pesquisadas destacaram que essas mudanças foram lentas e as transformações conviveram durante muito tempo com continuidades.

O objetivo desse artigo é, pois, compreender um aspecto do processo de construção do terceiro bairro de Natal capaz de demonstrar como essa modernização foi limitada e guiada

\footnotetext{
${ }^{2}$ Como exemplo tem-se a obra de Tavares de Lyra (membro da família Albuquerque Maranhão) sobre a história do estado, escrita em 1921, que enfatizou um passado fundador de uma identidade e de uma espacialidade norterio-grandense em que a ação dos antepassados de sua família teve papel primordial. Dessa maneira, não apenas Pedro Velho de Albuquerque Maranhão foi colocado enquanto herói fundador, mas outros membros de sua linhagem também foram imortalizados na obra como heróis de seus tempos. Para a compreensão de como a manipulação do imaginário social é importante em momentos de mudança política, social e de redefinição de identidades culturais, ver: CARVALHO, José Murilo. A formação das Almas: o imaginário da República no Brasil. São Paulo: Companhia das Letras, 1990.

${ }^{3}$ Neste artigo, o conceito de modernização empregado segue as discussões de Raymundo Faoro. Para o autor, a modernidade compromete em seu processo toda a sociedade, ampliando os papéis de todas as esferas sociais. Já a modernização é conduzida por um grupo específico, que privilegia os setores dominantes, "procura moldar, sobre o país, pela ideologia ou pela coação, uma certa política de mudança” (FAORO, 2012, p.8). Para a análise da realidade natalense no período estudado, o conceito de modernização é o mais adequado, uma vez que se observou em Natal a importância de determinados grupos no processo que conduziu as remodelações urbanas.
}

Oficina do Historiador, Porto Alegre, EDIPUCRS, v. 7, n. 1, jan./jun. 2014, p. 63-84. 65 
por um grupo específico. ${ }^{4}$ Assim, nesse texto buscar-se-á estudar o processo de desapropriações realizadas pelo poder local ao iniciar a construção de avenidas e residências padronizadas no novo bairro projetado. Também será investigada a situação dos moradores nesse processo de desapropriação, utilizando principalmente o discurso da oposição vinculado no jornal Diário do Natal, mas também o comparando com o discurso oficial, veiculado no $A$ República, que justificava essa intervenção. Dessa maneira, pretende-se estudar a construção discursiva do bairro Cidade Nova durante a Primeira República e as formações políticas no Rio Grande do Norte e, especificamente, em Natal, demonstrando como as críticas e denúncias do jornal oposicionista podem ser interpretadas como indícios de atividades ilícitas por parte de um governo patrimonialista, em um sistema político e cultural regido pelos interesses de quem ocupava o governo local.

\section{Os envolvidos na idealização do bairro Cidade Nova}

Como destacou Roger Chartier, "não há prática ou estrutura que não seja produzida pelas representações, contraditórias e confrontadas, pelas quais os indivíduos e os grupos dão sentido a seu mundo" (CHARTIER, 2002, p.66). Dessa maneira, é impossível estudar a formação do bairro Cidade Nova sem analisar os interesses do grupo político que idealizou esse território, que definiu regras para sua ocupação, que denominou suas ruas, praças e avenidas com nomes de presidentes do período, de rios importantes do estado e de líderes republicanos locais. A praça principal de Cidade Nova, por exemplo, foi denominada Praça Pedro Velho. Homenageava-se e exaltava-se na pedra o nome daquele indivíduo que liderou a organização familiar Albuquerque Maranhão e que foi responsável por consolidar a influência dessa família no Rio Grande do Norte a partir de 1895.

Segundo Sandra Pesavento, as cidades existem como representações simbólicas antes de serem concretizadas na realidade. "Por meio de discursos, imagens mentais, gráficos, desenhos e planos [as cidades] traduzem uma vontade e um sonho, que é o de transformar o espaço no sentido de concretização de uma ideia" (PESAVENTO, 1996, p.379). Para a autora, ainda que a cidade e suas instituições não se reduzam ao simbólico, elas não podem

\footnotetext{
${ }^{4}$ Este artigo é uma versão modificada e reduzida de parte do primeiro capítulo da dissertação da autora, ainda em fase de construção, intitulada provisoriamente de Por uma "Cidade Nova": construção e ocupação do terceiro bairro de Natal (1901-1929).
}

Oficina do Historiador, Porto Alegre, EDIPUCRS, v. 7, n. 1, jan./jun. 2014, p. 63-84. 66 
existir sem a constituição de uma ordem simbólica, capaz de articular uma rede de significações dotadas de coerência e sancionada socialmente. Partilhando das elucidações de Pesavento, considera-se que a construção do bairro Cidade Nova não pode ser analisada apenas em relação ao seu aspecto material.

Antes de ser concretizado enquanto bairro oficial, esse território foi pensado, imaginado, idealizado por determinado grupo, carregando interesses específicos. Todavia, embora se entenda que o bairro Cidade Nova foi construído para servir aos interesses de um determinado grupo, deve-se ressaltar que os espaços estão carregados de sentido para aqueles que os habitam ou que os frequentam, e que esses indivíduos também interferem na construção dos territórios criados pelo poder oficial, ajudando a concretizá-los de uma maneira diferente da que foi planejada pelo poder municipal e estadual. A análise da questão das desapropriações durante o processo de construção de Cidade Nova pode exemplificar uma consequência desse tipo de intervenção, guiada por um grupo específico, com objetivos sociais limitados, e que sofreu resistências, mesmo que sutis.

Nesse sentido, no esforço de construção de uma Natal modernizada também foi importante a atuação do Conselho da Intendência Municipal de Natal, que passou a ser responsável pela administração da cidade a partir de 1890 e era formado por representantes denominados intendentes. A Intendência publicava suas decisões na forma de resoluções, fundamentais para gerir a cidade em todos os seus aspectos: economia, trânsito, regras para aforamento, saúde, ensino, educação, entre outros. Várias resoluções regulamentaram a criação de ruas e praças no bairro Cidade Nova, bem como estabeleceram regras para delimitação dos terrenos, construções de moradias e modos de transitar no bairro planejado.

Alguns membros das famílias mais abastadas da cidade compunham a Intendência Municipal, juntamente com os representantes da família Albuquerque Maranhão. Os membros da Intendência Municipal eram indicados pela chefia estadual do Partido Republicano Federal e então eram levados à eleição. Em Natal, assim como na maior parte das cidades brasileiras nesse período, a oposição não tinha espaço. Os nomes indicados pelo partido estadual na maioria das vezes saiam vencedores, já que as eleições eram marcadas por processos fraudulentos e existiam relações de amizades e parentesco que ligavam os membros do governo estadual aos intendentes. A autonomia municipal garantida pelas constituições estaduais era na realidade um instrumento dos governos federais e estaduais para assegurar a vitória nas eleições (SANTOS, 2012). Na prática, o poder municipal era pouco autônomo, 
tendo, muitas vezes, que atender aos mandos e desmandos do grupo familiar que ocupava o governo estadual.

A presidência da Intendência era fundamental para a sustentação do grupo familiar na esfera estadual, uma vez que o presidente era também da junta apuradora de todas as eleições (SOUZA, 2008, p.165). Existiam ligações políticas que não se faziam apenas na esfera local, mas que dialogavam com a esfera estadual e nacional. Assim, o projeto de modernização da capital norte-rio-grandense ganhava forma a partir do esforço dos membros da família Albuquerque Maranhão e da Intendência Municipal do Natal na reformulação da cidade, em seus aspectos físicos, sociais e culturais.

Dando continuidade ao processo de modernização da cidade, a Intendência Municipal assinou em 1901 a Resolução n. 55, publicada no jornal A Republica em 04 de janeiro de 1902, determinando a criação do terceiro bairro da cidade:

[...] Art. $2^{\circ}$ - A Cidade Nova comprehenderá [...] quatro avenidas parallelas, com as denominações de Deodoro, Floriano, Prudente de Moraes e Campos Salles, cortadas por seis ruas com os nomes de Seridó, Potengy, Trahiry, Mipibú, Mossoró e Assú e duas praças, denominadas Pedro Velho e Municipal. A avenida que partindo da Praça Pedro Velho se dirige, no rumo do norte, para as dunas, terá o nome de Alberto Maranhão [...]. (A REPUBLICA, 04 jan. 1902, p.2).

O texto da Resolução n.55 já anunciava o desejo de modificar a forma de construir em Natal, estabelecendo padrões diferentes dos já existentes nos outros bairros da cidade (Ribeira e Cidade Alta). A Resolução determinava os espaçamentos que as construções deveriam respeitar no novo bairro. As ruas e avenidas de Cidade Nova não seriam estreitas e tortuosas como as da Ribeira e da Cidade Alta, existindo um padrão a ser seguido. Observa-se ainda como as toponímias do bairro demonstravam o interesse de fortalecer o discurso, de legitimar o grupo familiar que estava no poder e ressaltar o período republicano como responsável pelas mudanças evidenciadas na urbe. Existia um desejo de ligar o local ao nacional, de difundir a ideia de que finalmente a cidade e o estado acompanhavam as mudanças propiciadas pelo novo regime. A ideia era representar as mudanças como novas e o governo do período como precursor desse processo de modernização. 


\title{
A Cidade das Lágrimas
}

\author{
Lá na Cidade das Lágrimas \\ Vive o povo aperriado, \\ Quem não sahíu, entre cercas \\ De arame vê se cercado. (DIÁRIO DO NATAL, 13 jan. 1904).
}

Analisando a narrativa de Câmara Cascudo sobre o bairro Cidade Nova, observa-se que a região não possuía apenas chácaras de membros abastados e ligados ao grupo familiar Albuquerque Maranhão. Cascudo, ao comentar sobre a ação da Intendência na abertura e alinhamento das ruas e avenidas do novo bairro, destacou que "as raras choupanas que coincidiam com os traçados iam sendo desapropriadas ou vendidas, preço baixo, porque não havia valor para aquelas terras e gentes" (CASCUDO, 2010, p.331-332).

Nota-se como Cascudo tentou diminuir a importância da ação do governo estadual e da Intendência Municipal na desapropriação de residências de pessoas que habitavam a região. Provavelmente, o autor não estava fazendo menção às grandes propriedades construídas na área. O texto de Cascudo desqualificou essa população e suas habitações, possivelmente fazendo referência às 300 cabanas de retirantes da seca que também dividiam aquele território com as propriedades suntuosas dos mais abastados e sofreram um processo de desapropriação encabeçado pelo poder municipal.

O jornal Diário do Natal, de oposição, fundado por Elias Souto, fez constantes menções à derrubada de casebres existentes na região em que o novo bairro foi construído. Em virtude dessa ação de destruição de habitações de pessoas humildes, o jornal oposicionista apelidou Cidade Nova de Cidade das Lágrimas. Ao longo de todo o período de existência do jornal essa denominação foi mantida, como pode ser observado na epígrafe que abriu esse tema de estudo. O Diário do Natal publicou constantemente várias notícias denunciando a atitude desumana da Intendência, como destacou a matéria de janeiro de 1904 intitulada Cidade das lágrimas (DIÁRIO DO NATAL, 23 jan. 1904). Nessa matéria, o jornal apontou a derrubada de quatro casebres na área de Cidade Nova, deixando completamente desabrigados os seus “míseros donos”. Indivíduos que não eram referidos pelos seus sobrenomes, eram apenas o velho Bio, o proletário Faustino, e as infelizes Maria Preta e Anna Barauna. Segundo a notícia, essa derrubada, apelidada pelos redatores de "assalto aos casebres dos pobres", 
ocorreu para satisfazer os felizardos que desejavam abrir uma "tal rua" Mossoró para cercar de arame e construir sítios.

Observa-se como o processo de abertura de avenidas não ocorreu de forma imediata. O traçado da Rua Mossoró já tinha sido estabelecido em 1901 pela Resolução n.55, mas, como anunciou a matéria Cidade das lágrimas, essa rua só começou a ser construída em 1904, à custa da derrubada de vários casebres. A notícia ainda acusou o grupo familiar Albuquerque Maranhão de adquirir "esta fazenda para fazer dela um patrimônio" (DIÁRIO DO NATAL, 23 jan. 1904), afirmando que a construção do novo bairro estava sendo realizada para beneficiar apenas o grupo político que dominava o poder local, fazendo do patrimônio público extensões de suas propriedades privadas.

A notícia ainda continuou tecendo críticas à derrubada dos casebres, concluindo que a cidade estava enfrentando a pior fase de construção da "maldita Cidade das Lágrimas". Os últimos pobres estavam saindo a pulso, tendo suas casas, quintais e fruteiras destruídos. Para esses oposicionistas, o bairro não tinha nada de novo, apenas continuava reproduzindo os interesses dos mais abastados e influentes. Enquanto "choram os míseros para morrer com o seu pranto regam este bairro amaldiçoado, que constitui as delicias do grão senhor da terra" (DIÁRIO DO NATAL, 23 jan. 1904).

De fato, o Rio Grande do Norte enfrentou um desastroso período de secas no ano de 1904, fruto da estiagem que se prolongou desde 1902. A capital que possuía 16.056 habitantes, segundo o censo de $1900^{5}$, recebeu nesse ano aproximadamente 15 mil flagelados à procura de uma fonte de sobrevivência, fosse por meio da participação em trabalhos nas reformas urbanas da capital ou através de transporte para emigrar rumo a outros estados da região norte e sul do país (SOUZA, 2008, p.175). A cidade recebeu aproximadamente o dobro de sua população. Assim, esses indivíduos foram empregados em várias obras de melhoramentos urbanos da capital, inclusive na abertura de ruas e construção de chácaras em Cidade Nova. Muitos também foram vítimas de um processo forçado de migração, sendo embarcados nos navios que se destinavam à Amazônia para trabalhar nos seringais.

\footnotetext{
${ }^{5}$ Após o censo realizado em 1900 só ocorreu outra pesquisa estatística nesses moldes em 1910. Apesar de não ser possível afirmar com segurança, pode-se estimar que a população da cidade em 1904 não variou consideravelmente em relação ao ano de 1900, já que a população em 1910, dez anos depois, ainda era de 27.032 habitantes, ver: $\quad$ ESTATÍSTICAS do século XX. Disponível em:<http://www.ibge.gov.br/seculoxx/arquivos_pdf/populacao/1908_12/populacao1908_12v1_022.pdf>.

Acesso em: 16 abr. 2013.
} 
Imagem 1: Fotografia de 1904, feita por Bruno Bougard, destacando um grande número de retirantes da seca nas proximidades do Teatro Carlos Gomes, em Natal.

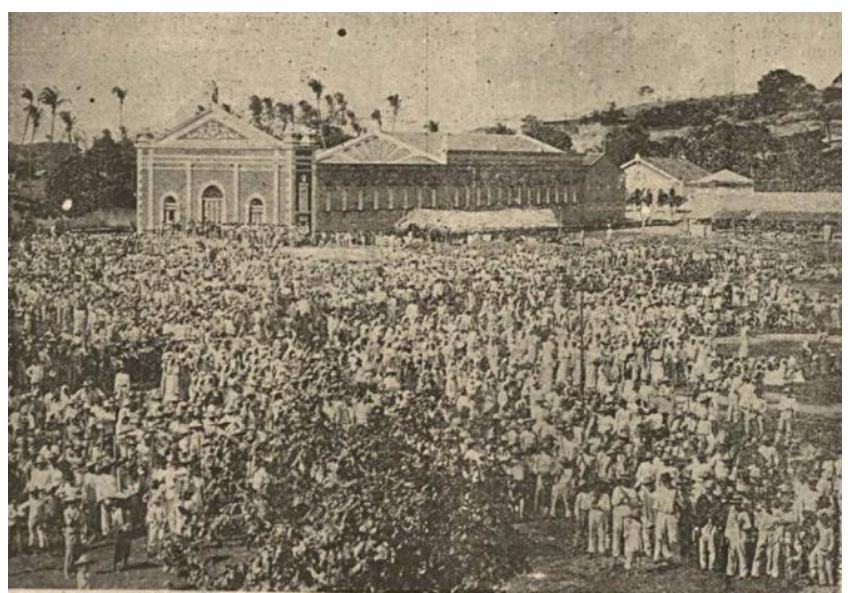

Fonte: O MALHO, Rio de Janeiro, ano III, n.106, 24 set. 1904.

Pela fotografia acima destacada, é possível ter noção da quantidade de retirantes que se dirigiram à capital norte-rio-grandense tentando fugir da assoladora seca que atingia o estado, sendo possível ainda conjecturar a intensidade do impacto que esses indivíduos provocaram na acanhada Natal do início do século XX. A imagem apresentou um grande número de sujeitos com vestes simples, enxadas nas mãos e com seus filhos ainda crianças nas proximidades do Teatro Carlos Gomes, no bairro Ribeira. Ainda pela fotografia, depreende-se como os flagelados dominavam toda a região próxima ao teatro, estavam concentrados para serem distribuídos em frentes de trabalho pela cidade. Contudo, o periódico fluminense $O$ Malho não veiculou mais informações sobre a fotografia, apenas apresentandoa acompanhada da seguinte legenda: "na praça principal da capital do Rio Grande do Norte, os flagelados partindo para os trabalhos públicos” (O MALHO, 24 set. 1904).

Para amenizar o problema da seca o governo federal, presidido nesse período por Rodrigues Alves, enviou o valor total de cento e setenta e cinco contos de réis (175:000.000) para o estado (SOUZA, 2008, p.320). O auxílio do governo federal foi também anunciado na mensagem do governador do estado Tavares de Lyra. Assim que assumiu o posto, no conturbado ano de 1904, o governador enviou um telegrama ao presidente informando a calamitosa situação do estado e pedindo auxílio financeiro. Observa-se como o poder local já fazia uso político da seca, utilizando-a como mecanismo para solicitar verbas para seu estado.

O presidente respondeu o telegrama enviando verbas para a construção de açudes, de poços e estradas. Além dessas reformas, a verba federal também foi destinada para custear 
passagens de "emigrantes voluntários que não pudessem encontrar trabalhos no Estado" (RIO GRANDE DO NORTE, 1904, p.15-16). Entretanto, esse embarque parece não ter sido tão voluntário como anunciou o governador do estado. Os que não embarcaram nesses navios foram divididos em quatro comissões para participar como mão-de-obra nas reformas urbanas da capital. Um desses grupos participou do processo de desmatamento e de abertura de várias avenidas do bairro Cidade Nova (SOUZA, 2008, p.320).

Segundo o Diário do Natal, esse processo já começou com irregularidades. Muitos desses flagelados da seca foram relocados para atividades particulares dos membros que dominavam a política local (DIÁRIO DO NATAL, 28 fev. 1904). O desvio da verba federal destinada a atenuar o problema dos flagelados da seca, o emprego de retirantes em obras particulares e a desapropriação desses flagelados de áreas de Cidade Nova podem indicar como o governo oficial atuava de forma patrimonialista e tentava fortalecer sua imagem em detrimento da exploração de determinada parte da sociedade local.

Em abril do mesmo ano outra matéria destacou a participação dos retirantes na construção da propriedade Solidão, residência de Pedro Velho. O jornal denunciava a utilização de flagelados da seca no carregamento de materiais para a referida chácara e adjacências, bem como o emprego de burros do serviço do governo no carregamento de estacas de ferro destinadas às obras públicas, fato que estava, segundo a notícia, sendo muito comentado (DIÁRIO DO NATAL, 07 abr. 1904). Não se tratava apenas do desvio de funções da mão-de-obra dos retirantes, que trabalhavam como "formigas" (DIÁRIO DO NATAL, 07 abr. 1904), sofrendo um processo exploratório apenas em troca de alimentação. A acusação era mais profunda. Materiais destinados a obras de melhoramentos urbanos da capital estavam sendo também desviados, mostrando mais uma vez como o dinheiro público estava sendo aplicado em benefício do líder da organização Albuquerque Maranhão, genro do então governador Tavares de Lyra.

Várias matérias do jornal Diário do Natal, sobretudo as intituladas Chronica Acreana, Cartas do Acre e Telegramas do Acre, publicadas a partir de fevereiro de 1904 e assinadas por Zébrasão ${ }^{6}$, criticavam esse processo de abertura de avenidas e de construção de grandes palacetes na região outrora habitada pelos retirantes e, sobretudo, denunciavam a participação desses retirantes nesse trabalho. Os flagelados da seca eram expulsos da região em que tinham

\footnotetext{
${ }^{6}$ Zébrasão ou José Brasão provavelmente eram pseudônimos utilizados pelo autor das crônicas acreanas. Infelizmente não foi possível localizar o nome oficial do autor dessas matérias.
} 
construído seus casebres e ainda obrigados a participar da construção do bairro que foi a razão da derrubada de suas residências. ${ }^{7}$

As cartas e telegramas acreanos faziam referência a acontecimentos do Rio Grande do Norte ressaltando, sobretudo, aqueles que se passavam na capital. Apesar de fazer referência ao governo local, essas matérias utilizavam elementos da história do Acre para, com humor, criticar os aspectos da administração vigente. Assim, Pedro Velho e os integrantes e simpatizantes do grupo familiar Albuquerque Maranhão eram denominados respectivamente de "general Pando" e de "pandos", tachados como aqueles que só queriam beneficiar-se em detrimento da exploração alheia.

$\mathrm{Na}$ história do Acre, observa-se a existência de um personagem com o sobrenome "Pando". José Manuel Pando, também conhecido como General Pando, foi presidente da Bolívia entre 1899 e 1904, período em que o território do Acre foi alvo de disputa entre brasileiros e bolivianos. Os conflitos acirraram-se em 1902 e foram concluídos em 1903, quando as tropas bolivianas foram derrotadas. Por intermédio do Barão de Rio Branco, foi negociado um armistício entre os dois países em conflito, até que, em 17 de novembro do mesmo ano, ocorreu a conciliação e o término das disputas bélicas na região do Acre com a assinatura do Tratado de Petrópolis. Por esse tratado, territórios foram permutados, indenizações foram estabelecidas e o Brasil passou a ter domínio sobre a região acreana (TRINDADE, 2003). O General Pando era frequentemente representando na versão brasileira sobre o conflito como aquele que queria usurpar a região acreana que pertencia de fato e de direito ao Brasil.

Notícias sobre os conflitos existentes na região eram bastante divulgadas no jornal oficial A Republica. Em1903, por exemplo, várias matérias foram publicadas noticiando os episódios que ocorriam na chamada "Revolução Acreana". 8 Algumas dessas matérias eram escritas por oficiais brasileiros que estavam vivenciando diretamente o conflito no Acre, destacando minuciosos aspectos da região em longas e detalhadas cartas.

As alusões do Diário do Natal comparando a história local com aspectos da história acreana referem-se a esse momento, em que o Acre era uma alternativa do governo estadual

\footnotetext{
${ }^{7}$ Várias matérias publicadas no jornal oposicionista destacaram a utilização dos retirantes da seca em trabalhos particulares, sobretudo na chácara do líder do grupo familiar Albuquerque Maranhão, Pedro Velho: TELEGRAMAS do Acre. Diário do Natal, Natal, 19 maio 1904. p.1; DIÁRIO do Natal, Natal, 21 maio 1904. p.1; DIÁRIO do Natal, Natal, 22 maio 1904. p.1; NEMO. De meu canto. Diário do Natal, Natal, 24 maio 1904.

${ }^{8}$ Em 1903 várias matérias foram publicadas no jornal oficial ressaltando a iniciativa dos oficiais brasileiros, juntamente com o povo acreano, nos conflitos contra os bolivianos. Essas matérias destacaram o caráter patriótico dessa disputa por um território bastante lucrativo economicamente, já que a extração de borracha nesse período era uma atividade muito rentável, ver: O ACRE. A Republica, Natal, 16 jul. 1903. p.1; O ACRE. A Republica, Natal, 04 set. 1903. p.2; O ACRE. A Republica, Natal, 18 nov. 1903. p.1.
}

Oficina do Historiador, Porto Alegre, EDIPUCRS, v. 7, n. 1, jan./jun. 2014, p. 63-84. 
para resolver o problema dos migrantes norte-rio-grandenses. Provavelmente a comparação de Pedro Velho com o General Pando visava sugerir que o ex-governador estava dando um "golpe" no estado, querendo beneficiar-se de verbas públicas em detrimento da exploração da população, governo que seria ilegítimo, segundo o autor das Cartas do Acre. Muitos Telegramas do Acre e outras matérias do jornal oposicionista compararam essa migração com a comercialização de escravos.

Talvez a alusão ao Acre tenha sido elaborada no intuito de criticar mais ferrenhamente essa migração de retirantes forçada pelo governo norte-rio-grandense, sem esquecer a pitada de humor que a alusão oferecia, o que poderia atrair a curiosidade de um maior número de leitores. De fato, as vendas do jornal oposicionista aumentaram após a publicação constante dessas colunas, como destacou a matéria de março de 1904 intitulada Edição Exgotada. Apesar da tiragem do jornal oposicionista ser de 200 exemplares, todas as vezes que as colunas referentes ao Acre eram publicadas a edição esgotava-se. (DIÁRIO DO NATAL, 01 mar. 1904).

Partindo para a análise das crônicas, cartas e telegramas acreanos, observa-se, que desde o primeiro número, publicado em 19 de fevereiro de 1904, as críticas eram ferrenhas. O autor sempre usava as obras de construção de Cidade Nova como exemplos de falcatruas e patrimonialismo do governo local. Nesse primeiro número, Zebrasão destacou que no processo de construção do bairro a "roubalheira" era a característica principal. Homens que antes de estabelecerem vínculos com o grupo familiar Albuquerque Maranhão eram pobres, sem posses, estavam tornando-se verdadeiros feitores, construindo obras suntuosas a custa do dinheiro público. A matéria apontou os fiscais da Intendência como os maiores "viveiros dessa horda de comedores" e destacou que os presidentes do governo municipal eram verdadeiros "déspotas absolutos", criando em suas gestões os impostos que desejavam, apropriando-se do dinheiro do povo (DIÁRIO DO NATAL, 19 fev. 1904).

Outra Carta do Acre que continuou tecendo críticas ao enriquecimento dos funcionários públicos foi a publicada em abril desse mesmo ano. José Brazão iniciou a carta destacando que um novo governador tinha assumido o poder no estado, e, embora "genro do Pando", prometia melhorar as "patifarias" da política local. Observa-se a explícita alusão que o autor da carta fez ao então governador Tavares de Lyra, que, como elucidado, era genro de Pedro Velho (LYRA, 1974, p.57). Zébrazão continuou as acusações, apontando que os funcionários do governo faziam do dinheiro estadual e municipal um meio de vida para a construção de casas e palacetes de mais de 50 contos de réis, muito dinheiro para um estado 
que enfrentava grande crise agravada pelo período de estiagem (DIÁRIO DO NATAL, 23 abr. 1902).

Em várias matérias, Zebrazão deixou explícito que não era fácil escrever denunciando os mandos e desmandos dos verdadeiros criminosos que ocupavam os cargos de poder no Acre, ou seja, no Rio Grande do Norte. O autor também denunciava as intimidações que sofria do governo estadual e municipal, que ameaçavam destruir a tipografia do Diário caso as crônicas não deixassem de ser publicadas. ${ }^{9}$ Mesmo diante das ameaças, Zebrazão continuou publicando as colunas referentes ao Acre durante todo o ano de $1904 .^{10}$

Outras matérias destacavam que Pedro Velho e sua família não pagavam os impostos cobrados pelo governo municipal e estadual, não existindo na repartição pública quem tivesse coragem de cobrar essa que se constituía em uma verdadeira "família real" (DIÁRIO DO NATAL, 15 maio 1904). Família que utilizava o dinheiro público para custear propagandas de seu governo no "Re-Porca", como Zebrazão fazia alusão ao jornal oficial do Partido Republicano Federal do Rio Grande do Norte, o A Republica (DIÁRIO DO NATAL, 02 jul. 1904). Em julho de 1904 o autor das cartas e telegramas acreanos faleceu, mas no mesmo mês outro autor assumiu o pseudônimo Zébrazão e continuou a tecer críticas ao governo local como se estivesse construindo análises do governo do Acre. A antiga coluna Carta Acreana foi substituída pela Chronica Acreana (DIÁRIO DO NATAL, 12 jul.1904).

O novo autor era ainda mais irônico e ácido que o antigo José Brazão, fazendo críticas cada vez mais ferrenhas ao poder local. Em sua primeira crônica, o novo Zebrazão já demonstrou que suas denúncias não seriam nada sutis, destacando que o estado estava submetido ao governo do Lorota, em alusão ao então governador Tavares de Lyra, que era "automato, imbecil, que se submete cegamente às exigências de uma politicagem corrupta e absorvente" (DIÁRIO DO NATAL, 13 jul. 1904). Ou seja, as esperanças que o antigo José Brazão depositava no governo de Lyra foram destruídas pelo novo autor das crônicas. Segundo o autor, enquanto o povo morria de fome, o novo governador tratava de embelezar a cidade, construindo jardins, gastando semanalmente ricas somas de dinheiro em espetáculos no Teatro Carlos Gomes e em reformas de suas propriedades no bairro Cidade Nova. A capital estava, portanto, entregue ao "canibalismo de um aventureiro, que entendeu perpetuar-

\footnotetext{
${ }^{9}$ São exemplos de matérias que demonstram essa dificuldade de publicação das cartas acreanas e as ameaças sofridas pelo autor: CARTAS do Acre. Diário do Natal, Natal, 09 abr. 1904.p.2.

${ }^{10}$ Durante a denominada Primeira República no estado a prática de perseguição à imprensa oposicionista foi constante, sobretudo durante o governo de Tavares de Lyra (1904-1906). No ano de 1913, durante a segunda gestão de Alberto Maranhão, o Diário do Natal foi empastelado, ação que colocou fim à atuação desse jornal oposicionista que foi tão expressivo no início do século XX, ver: SOUZA, Itamar de. A República Velha no Rio Grande do Norte. Natal: Editora da UFRN, 2008. P.248-251.
}

Oficina do Historiador, Porto Alegre, EDIPUCRS, v. 7, n. 1, jan./jun. 2014, p. 63-84. 
se na direção dos negócios públicos, com o que tem aniquilado essa terra, outrora tão feliz" (DIÁRIO DO NATAL, 13 jul. 1904).

Várias crônicas do novo Zébrasão anunciavam o envio de praças de Polícia para propriedades de membros da família Albuquerque Maranhão que moravam no bairro Cidade Nova. Esses policiais deveriam fazer a guarda das propriedades e impedir que os retirantes incomodassem seus ilustres moradores. Merece destaque a crônica publicada em 15 de outubro de 1904, que denunciou esse abuso de mandar surrar os retirantes sem ter causa definida, somente por "ostentação de perversidade" desses que eram "desalmados inimigos do povo" (DIÁRIO DO NATAL, 15 out. 1904).

[...] Num dia de sabbado, alguns retirantes, saudosos de seus lares, depois de haverem percorrido os mangues em busca de crustáceos, com que mal fizeram a alimentação do dia, [...] formaram um atabaque, para as bandas da Pretoria, do Dr. Porquinho. Ao som de uma viola gemedeira, depois de uma execução de Sambê, passaram a cantarollar [...]:Sinha Anninha, eu vou me embora,Vou morrer no meu sertão [...].Ai!...Sinha Anninha [...]. Soccorros de quando em quando manda o chefe da Nação; Mas o que nos dá o Pando é a surra de facão. Ai! Sinha Anninha [...]. A esse tempo diversas praças de policia chegaram ao samba, mandadas pelo respectivo Delegado e requisitadas pelo Dr. Poquinho; quebraram viola, surraram o cantador, e espalharam o resto do povo. Pobres famintos acreanos que nem podem ao menos cantar suas desgraças [...]. (DIÁRIO DO NATAL, 15 out. 1904).

Nota-se mais um episódio que indica como os moradores mais abastados de Cidade Nova usavam de seus poderes e influências para prejudicar os flagelados da seca, reforçando que não queriam dividir aquele bairro com esses retirantes. Provavelmente o Dr. Porquinho citado na crônica por Zébrasão era o Dr. Manoel Dantas, uma vez que, conforme destacou Alberto Maranhão em carta para Cascudo na década de 1940, Dantas era proprietário da Vila Pretoria, localizada em Cidade Nova. (CASCUDO, 2010, p.333). Manoel Dantas, bacharel em Direito, jornalista, professor, redator chefe do A Republica nesse período (SANTOS, 2012, p.180), também era bem relacionado com o grupo familiar Albuquerque Maranhão, talvez por isso Zebrazão colocou-o como o protagonista desse trágico episódio ocorrido em Cidade Nova.

É válido destacar que essas crônicas, até pelo elemento ficcional que carregam (a alusão a episódios da história acreana), não podem ser consideradas como expressões da verdade, assim como outros tipos de fontes analisadas nesse artigo. Não foram encontrados documentos oficiais que embasassem essas acusações, mas isso não quer dizer que elas não 
existiram. Não quer dizer que o espancamento dos retirantes não foi uma realidade. O fato é que essas denúncias foram elaboradas por um jornal oposicionista, contrário ao governo, que pode muito bem ter exagerado nas acusações.

Todavia, para a análise desenvolvida nesse texto não importa se o episódio realmente aconteceu. O que está sendo analisado são as representações do bairro Cidade Nova e das reformas urbanas da capital que foram elaboradas pelos opositores do governo local, comparando-as com as representações oficiais expressas nas mensagens de governadores, relatórios de intendentes e matérias do jornal A Republica. O cruzamento dessas versões é o que dá subsídios para demonstrar se a construção de Cidade Nova como discurso de bairro modernizado, novo, progressista teria mesmo concretizado-se na prática. Por isso é importante frisar que as matérias oposicionistas comentadas são versões elaboradas pelos redatores do Diário do Natal e devem ser analisadas como tais. Como ressaltou Pesavento, a cidade é objeto de múltiplos discursos e olhares, que não se hierarquizam, mas que se justapõem, compõem ou se contradizem, sem ser um mais verdadeiro ou importante do que os outros (PESAVENTO, 2002, p.9).

A imagem reproduzida no Diário em junho de 1904 pode resumir todas as críticas veiculadas no jornal de oposição:

Imagem 2: Representação de um dos banquetes realizados na propriedade de Pedro Velho em Cidade Nova.

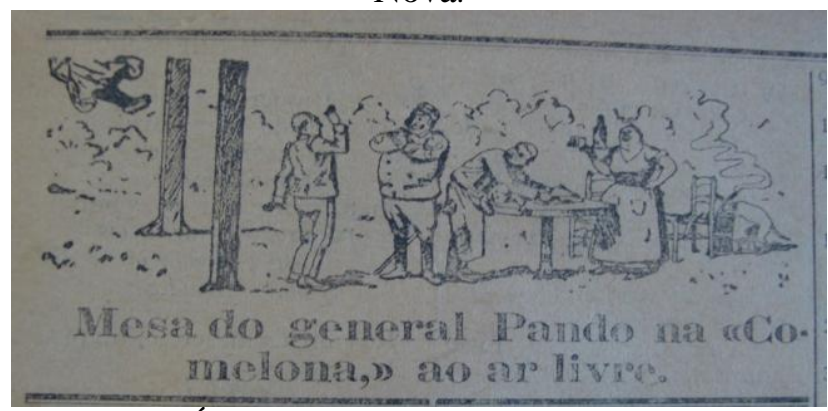

Fonte: DIÁRIO do Natal, Natal, 23 jun. 1904. p.3.

A imagem representou um dos acontecimentos frequentes nas propriedades existentes em Cidade Nova: os banquetes e piqueniques oferecidos para a sociedade abastada do período. Os opositores retrataram um banquete organizado na propriedade de Pedro Velho, marcado por uma sensação de satisfação. ${ }^{11}$ Os personagens que integraram a cena do banquete são robustos, cheios, parecem bem alimentados. A fartura do evento é também

\footnotetext{
${ }^{11}$ No início do século XX, os jornais locais não publicavam muitas imagens. Essa sátira em forma de figura é ainda mais interessante pelo seu caráter de raridade, sendo a única ironia em forma de imagem encontrada nesse periódico durante a pesquisa.
}

Oficina do Historiador, Porto Alegre, EDIPUCRS, v. 7, n. 1, jan./jun. 2014, p. 63-84. 
destacada pela imagem dos cachorros à direita da ilustração. A quantidade de alimentos era tamanha, que sobrava até mesmo para os animais, que também podiam se satisfazer com a abastança do líder do grupo familiar Albuquerque Maranhão. Os animais podem ainda representar os flagelados da seca, aqueles que tinham que se contentar com as migalhas desse poder local.

Pedro Velho possivelmente é o segundo personagem da esquerda para direita, com pose robusta, semelhante a de um general. É a figura central da imagem, para quem todos os outros sujeitos representados estão olhando, em sinal de atenção e submissão. Na imagem também aparecem duas colunas de madeira, provavelmente representando a delimitação do terreno, sinalizando que aquela área, apesar de estar ao ar livre, era delimitada, cercada, tinha dono, pertencia a Pedro Velho.

A imagem resume de forma irônica as várias críticas presentes nas crônicas, telegramas e cartas do acre e em outras matérias do jornal Diário do Natal já comentadas. A figura parece denunciar a fartura dos membros do poder estadual e local, enquanto os pobres retirantes da seca sofriam com a falta de habitação, já que suas cabanas estavam sendo derrubadas para dar lugar às largas avenidas de Cidade Nova. Os flagelados da seca também não tinham uma alimentação adequada nem segurança, sendo frequentemente espancados pelas ruas da cidade, segundo o jornal oposicionista. Enquanto sofriam, o General Pando, Pedro Velho, e sua rede de parentela e amizade deleitavam-se no território que outrora fora também marcado pelas choupanas dos retirantes. As cercas possivelmente indicam esse processo de "cercamento", de demarcação do espaço dos mais abastados, que muitas vezes era feito à custa do dinheiro público.

Mesmo com o envio de verbas federais e com o incremento das obras de melhoramentos urbanos de Natal, o governo estadual não conseguiu atender todos os retirantes que se aglomeravam na capital. A situação começou a ficar cada vez mais precária, resultando no início de convulsões sociais, com movimentações populares pelas ruas da cidade e saques no comércio. Situação que ainda foi agravada pela epidemia de varíola que atingiu a cidade e perdurou até 1905 (FERREIRA et al, 2006, p.57). O jornal oposicionista também comentou as revoltas encabeçadas pelos flagelados da seca que se espalhavam pela cidade. Muitos retirantes começaram a atacar armazéns de gêneros alimentícios, como destacou a matéria de abril de 1904. Nesse episódio registrado pelo Diário, os retirantes rasgaram sacos de bolacha durante o saque, que contou com a intervenção da Polícia, 
“tangendo" a facão os famintos (DIÁRIO DO NATAL, 27 abr. 1904). Os flagelados revidaram jogando pedras nos policiais. No final do conflito, vários retirantes ficaram feridos.

Imagem 3: Fotografia feita por Bruno Bougard em 1904. Imagem que demonstra vários retirantes em manifestação no bairro Cidade Alta.

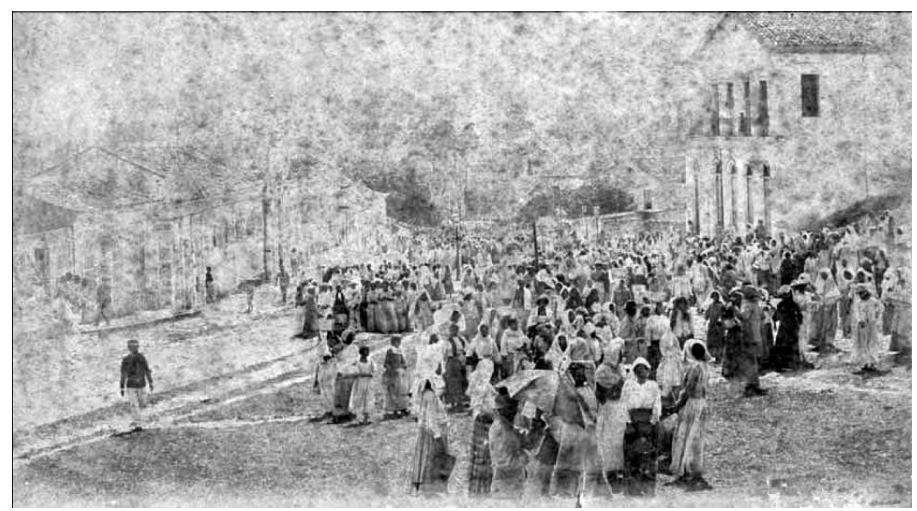

Fonte: Acervo particular de Anderson Tavares.

A expressiva fotografia de Bougard demonstra como o ano de 1904 foi conturbado e ambivalente, marcado por expressivas tensões. A cidade estava sofrendo um processo de remodelação. Ruas eram abertas, jardins eram construídos, a reforma do teatro foi concluída, mas milhares de flagelados chegaram à capital de um estado que enfrentava uma assoladora seca. Os membros do poder local tinham que lidar com essa população, em um momento no qual o discurso sanitarista era forte. Nesse período em que os membros abastados estavam dando prosseguimento ao processo de segregação espacial com a construção de um bairro afastado dos dois outros existentes, esses retirantes desafiavam a ordem, ameaçavam a higiene e o processo de modernização tão exaltado no jornal oficial. Era preciso tentar resolver esse problema, e a solução encontrada foi o embarque muitas vezes forçado desses indivíduos para trabalhar nos seringais do Norte ou nos cafezais do Sul e o emprego dos muitos que ficaram nessas obras de melhoramento da cidade.

Nada mais ambivalente do que uma modernização custeada pelo trabalho de flagelados da seca. Eis a Natal que iniciava o século XX, que queria fazer-se moderna, mas enfrentava sérios problemas. Retirantes que, como indicam algumas matérias do Diário e o instantâneo de Bougard, não parecem ter aceitado essa situação de forma tão pacífica. A imagem demonstra uma reunião de flagelados da seca no bairro Cidade Alta em frente à residência do então governador Tavares de Lyra, clamando por assistência. Infelizmente não foi possível localizar mais fontes que destacassem a participação desses retirantes em outros conflitos e protestos na cidade, mas as poucas informações encontradas oferecem indícios da 
existência dos mesmos, demonstrando que esses retirantes não encararam a nova realidade passivamente.

Retornando ao problema que abriu esse artigo, a derrubada dos casebres existentes na área em que o bairro Cidade Nova foi construído, é necessário também apresentar o discurso oficial sobre essa desapropriação. Para tanto, a análise do relatório trienal do então intendente Joaquim Manoel Teixeira de Moura, que era bem relacionado com a família Albuquerque Maranhão, torna-se essencial. Joaquim Moura foi presidente da Intendência de Natal entre 1901 e 1913, casando, em 1909, sua filha com o filho de Pedro Velho (A REPUBLICA, 18 mar. 1909).

Em janeiro de 1905, o então intendente divulgou um relatório referindo-se à gestão da Intendência entre 1902 e 1904, que foi publicado em várias edições do jornal A Republica. Nesse relatório o presidente da Intendência exaltou as reformas e melhoramentos que estavam colocando à capital em uma "era nova de prosperidade e conforto" (A REPUBLICA, 13 jan. 1905). O intendente enfatizou a dificuldade no processo de implementação de reformas em uma cidade que foi marcada por uma formação não geométrica, por praças e avenidas tortuosas e esburacadas, e nesse momento vivia uma remodelação profunda, com a abertura de avenidas planejadas e marcadas pelo aspecto retilíneo. Observa-se como Joaquim Manoel reforçou, em seu relatório, o discurso de mudança tão destacado pelo poder estadual. O poder municipal, como já analisado, estava em consonância com os interesses estaduais, por isso essa exaltação, por isso o reforço da representação da cidade como vivendo uma nova fase. $\mathrm{O}$ intendente comentou ainda sobre a construção de Cidade Nova, em que:

[...] um matagal semeado de cabanas em desordem acha-se substituido por uma serie de largas avenidas e ruas, cujo aspecto já é bastante agradavel. Perto de tresentas casinholas e ranchos foram indemnisados e removidos do trajecto das ruas do referido bairro; [...]com a ausencia completa de miasmas, a larga ventilação marinha e outras vantagens hygienicas, não tardará a ser a habitação preferida. (A REPUBLICA, 14 jan. 1905).

Nota-se como o presidente da Intendência vangloriou-se pela abertura do novo bairro ter ocorrido durante a sua gestão à frente da Intendência, gestão que se perpetuará até 1913. Observa-se ainda como Joaquim Manoel abordou o problema da desapropriação dos casebres existentes em Cidade Nova. Segundo o intendente, esses não foram derrubados com violência, seus moradores não foram expulsos como gente sem valor, conforme exposto pelas matérias do jornal oposicionista. Para a Intendência, já que Joaquim Manoel representava essa 
instituição nesse relatório, essas propriedades foram removidas por meio de um processo de indenização. Contudo, em nenhum momento do seu relatório foi informado para onde essa população foi removida e o valor dessas indenizações. $\mathrm{O}$ intendente nem ao menos destacou a quem pertenciam essas propriedades, não se referindo aos retirantes da seca em nenhuma passagem desse relatório.

Como a citação do relatório de Joaquim Manoel demonstra, o discurso oficial procurou justificar essa atuação de desapropriação, elucidando como o novo bairro seria higiênico e salubre e, em um futuro próximo, o local preferido da cidade para a construção de habitações que respeitassem a padronização do período. Essa afirmação ainda revelou como, em 1905, após quatro anos de sua idealização, o bairro ainda não tinha sido concretizado como esperado. Sobre as indenizações que teriam sido pagas pela Intendência aos moradores dos casebres que foram derrubados, o jornal oposicionista ressaltou que nesse processo o direito de propriedade não foi respeitado e aquela população foi tradada de forma desumana. Segundo os redatores do Diário, "as idemnizações não attingiram nem a terça parte do valor das propriedades destruídas" (DIÁRIO DO NATAL, 05 jan. 1908).

O jornal A Republica não fez mais nenhuma menção à desapropriação desses indivíduos que habitavam os casebres existentes na área antes da intervenção do poder local. Também não foi encontrada nenhuma referência dessa desapropriação em outros relatórios oficiais e nas mensagens de governadores. Todavia, como foi demonstrado nesse artigo, o bairro também foi ocupado por pessoas menos abastadas e, provavelmente, esses retirantes não foram totalmente expulsos da área que originaria a Cidade Nova. A nova Natal, a nova cidade, conviveu com diversas continuidades. A mudança de costumes tão arraigados demorou muito tempo para ser concretizada, se é que realmente o foi.

É necessário destacar que as críticas e acusações do jornal Diário do Natal devem ser redimensionadas. Tratava-se de um jornal oposicionista, que tinha sérias simpatias e saudosismo pelo regime monárquico e acusava frequentemente os Albuquerque Maranhão e sua rede de parentela e amizade por terem ajudado na implantação do regime republicano no estado, depondo o regime pelo qual simpatizavam. Assim, essas denúncias muitas vezes baseadas apenas na observação dos redatores e utilizando metáforas, sem citar documentos que comprovassem as acusações, devem ser observadas com criticidade. Do mesmo modo que os membros que dominavam o poder local representavam seus interesses de forma exagerada no jornal oficial A Republica, sempre tentando exaltar a grandiosidade das reformas que imprimiam na cidade, reformas que muitas vezes ficavam apenas na idealização, 
o jornal Diário do Natal também servia de espaço para os grupos oposicionistas. Grupos muitas vezes recalcados por não terem reconhecimento na política local e que utilizavam o Diário para representarem-se, criarem também os seus discursos.

Vale ressaltar ainda que Natal no início do século XX não era uma cidade de grandes dimensões e possuidora de variados espaços de sociabilização, o que obrigava constantemente os membros oposicionistas a encontrarem-se com os ocupantes do governo oficial, obrigandoos a manterem a cordialidade em muitos eventos. O jornal oposicionista também publicava notas parabenizando parentes de Pedro Velho durante seus natalícios e membros que estavam no poder na Intendência Municipal. Após o falecimento do líder dos Albuquerque Maranhão, por exemplo, o Diário publicou uma extensa nota exaltando Pedro Velho, destacando que, com o seu falecimento, o Rio Grande do Norte tinha sido privado de um de "seus filhos mais ilustres, a politica de um timoneiro inteligente e sagaz e a família de um chefe muito dedicado, extremoso e previdente" (DIÁRIO DO NATAL, 11 dez. 1907). Observa-se como o outrora tão criticado Pedro Velho foi glorificado pelo jornal oposicionista nessa nota, demonstrando como a oposição entre esses dois periódicos era relativa.

De fato, a oposição existia. O Diário sempre comentava os fatos da política local e estadual com ironia e criticidade, entretanto, o que se quer destacar é que essa oposição não era unívoca, não impedia a cordialidade entre membros de partidos opostos nas ocasiões de sociabilização que ocorriam na capital. Assim como o jornal oficial não publicava apenas matérias elogiando o governante da vez. Nesse periódico encontram-se denúncias e reclamações em relação ao poder municipal e estadual em vigor.

Logo, as críticas e denúncias do jornal oposicionista podem e devem ser interpretadas como indícios de atividades ilícitas por parte de um governo patrimonialista, em um sistema político e cultural regido pelos interesses de quem ocupava o governo local. Realidade que não era exclusiva do Rio Grande do Norte, situação que foi igualmente partilhada por muitos estados durante a denominada Primeira República. Contudo, essas críticas também devem ser redimensionadas, ou seja, entendidas enquanto representações de um grupo oposicionista, mas que também estava frequentemente convivendo com os grupos políticos dominantes nos territórios da pequena capital norte-rio-grandense. 


\section{Considerações finais:}

Ao longo desse artigo tentou-se reconstruir as condições que impulsionaram uma série de reformas em Natal, implementadas por um grupo que adquiriu prestígio político e social com a implantação do regime republicano. Esse grupo tentava legitimar seu poder e representar-se nessas mudanças, ressaltando o caráter de novidade que traziam para remodelar aquela capital que, segundo esse discurso, fora tão desprezada no período imperial. Também foi possível observar como o processo de idealização e construção do terceiro bairro oficial da cidade envolveu a desapropriação e derrubada de muitos casebres existentes na região, que passou a ser denominada pelo jornal oposicionista de Cidade das Lágrimas.

De fato, foi possível constatar como o poder municipal, com o auxílio do governo estadual, transformou uma área já existente na parte suburbana da cidade em um bairro oficial, criando um território que foi bastante exaltado nas matérias do jornal A Republica como bairro do futuro, do progresso, que viria representar a nova condição política do estado. Contudo, a análise das matérias veiculadas pelo jornal oposicionista bem como a comparação dessas com a voz do jornal oficial é capaz de fornecer indícios que podem sustentar como a construção do terceiro bairro oficial não foi realizada tal qual projetado pelo grupo que dominava o poder estadual e irradiava-se pelo poder local.

O estudo dos discursos sobre a desapropriação dos retirantes da seca ajuda a demonstrar como o bairro Cidade Nova pode ser tido como um exemplo significativo desse processo de modernização da Natal do início do século $\mathrm{XX}$, guiado por um grupo mais abastado e influente e caracterizado por mudanças sociais limitadas. A história do bairro é representativa dos interesses políticos, sociais e econômicos daqueles que ocuparam o poder local em Natal na realidade da Primeira República.

\section{REFERÊNCIAS BIBLIOGRÁFICAS}

CARONE, Edgar. A República Velha: I instituições e classes sociais (1889-1930). Rio de Janeiro: Difel, 1983.

CARVALHO, José Murilo. A formação das Almas: o imaginário da República no Brasil. São Paulo: Companhia das Letras, 1990. 
CASCUDO, Luís da Câmara. História da Cidade do Natal. Natal: EDUFRN, 2010.

CHARTIER, Roger. À beira da falésia: a história entre incertezas e inquietudes. Porto Alegre: Editora da UFRGS, 2002.

FAORO, Raymundo. A questão nacional: a modernização. Estudos avançados, São Paulo, v. 6, n.14, Apr. 1992. Disponível em:

<http://www.scielo.br/scielo.php?script=sci_arttext\&pid=S010340141992000100002\&lng=en $\& n r m=i s o>$. Acesso em 04 jul. 2012.

FERREIRA, Angela Lúcia e DANTAS, George (orgs). Surge et Ambula: A construção de uma cidade moderna (Natal, 1890-1940).Natal: Editora da UFRN, 2006.

LYRA. Sophia A. Rosas de Neve: como eram as mulheres no começo do século. Rio de Janeiro: Editora Cátedra, 1974.

PEIXOTO, Renato Amado. Espacialidades e estratégias de produção identitária no Rio Grande do Norte no início do século XX. In: PEIXTO, Renato Amado (Org.). Nas trilhas da representação: trabalhos sobre a relação entre história, poder e espaços. Natal: Editora da UFRN, 2012.

PESAVENTO, Sandra Jatahy. O imaginário da cidade: visões literárias do urbano-Paris, Rio de Janeiro, Porto Alegre. Porto Alegre: Editora da UFRGS, 2002.

SANTOS, Renato Marinho Brandão. A elite que administrou a cidade do Natal na Primeira República. In:_. Natal, outra cidade!: o papel da Intendência municipal no desenvolvimento de uma nova ordem urbana (1904-1929). Dissertação (Mestrado em História) - Programa de Pós-Graduação em História, Universidade Federal do Rio Grande do Norte (UFRN), Natal, 2012.

SOUZA, Itamar de. A República Velha no Rio Grande do Norte. Natal: Editora da UFRN, 2008.

TRINDADE, Luciano José. Apontamentos sobre a consolidação do território do estado do Acre: das disputas entre Portugal e Espanha à fixação definitiva da divisa interestadual Acre/Amazonas. Disponível

em <http://www.pge.ac.gov.br/site/arquivos/bibliotecavirtual/revistas/revista10/apontamentosobr eaconsolidacao.pdf $>$. Acesso em: 14 abr. 2013.

ARTIGO ENVIADO PARA PUBLICAÇÃO EM: 03.07.2013 ACEITO PARA PUBLICAÇÃO EM: 29.09.2013 